\title{
Common Carotid Artery Branch
}

National Cancer Institute

\section{Source}

National Cancer Institute. Common Carotid Artery Branch. NCI Thesaurus. Code C32353.

Any artery that takes its origin from the common carotid artery, most commonly the internal carotid artery and external carotid artery. 